Annals of Pure and Applied Mathematics

Vol. 14, No. 2, 2017, 231-235

ISSN: 2279-087X (P), 2279-0888(online)

Published on 31 August 2017

www.researchmathsci.org

DOI: http://dx.doi.org/10.22457/apam.v14n2a4

Annals of

Pure and Applied

Mathematics

\title{
Topological Indices of the Total Graph of Subdivision Graphs
}

\author{
Mohanappriya. $G^{1}$ and D.Vijayalakshmi ${ }^{2}$ \\ PG and Research Department of Mathematics \\ Kongunadu Arts and Science College \\ Coimbatore-641029, Tamil Nadu, India. \\ Corresponding author. E-mail: mohanappriyag25@gmail.com
}

Received 11 August 2017; accepted 28 August 2017

Abstract. In this paper, we compute topological indices of the total graphs of the tadpole graphs, wheel graphs and ladder graphs using the subdivision concept, which extend the results of Ranjini et al. (2011).

Keywords: Topological index, line graphs, total graphs, subdivision graphs, tadpole graphs, wheel graphs, ladder graphs

AMS Mathematics Subject Classification (2010): 05C05, 05 C07

\section{Introduction}

Unless stated otherwise all graphs considered here are finite, simple and undirected. Let $\mathrm{G}$ be such a graph with vertex (node) set $\mathrm{V}(\mathrm{G})(|\mathrm{V}(\mathrm{G})|=\mathrm{n})$ and edge set $\mathrm{E}(\mathrm{G})(|\mathrm{E}(\mathrm{G})|=$ $\mathrm{m}$ ). The degree (or valency) of a vertex $\mathrm{v}$ denoted by $\mathrm{d}_{\mathrm{v}}$ is the number of edges incident to $\mathrm{v}$. The line graph, [7], of the graph $\mathrm{G}$, written $\mathrm{L}(\mathrm{G})$, is the simple graph whose vertices are the edges of $\mathrm{G}$, with ef $\epsilon \mathrm{E}(\mathrm{L}(\mathrm{G}))$ when e and $f$ have a common end point in $\mathrm{G}$. An extension of the notion of line graph is the graph valued function known as atal graph. The total graph [7] of $G$, denoted by $T(G)$, is the graph whose adjacent vertices corresponds to the union of the set of vertices and edges of $G$, with two vertices of $T(G)$ is being adjacent if and only if the corresponding element are adjacent or incident in G. The Subdivision graph [7], $\mathrm{S}(\mathrm{G})$ is the graph attained from $\mathrm{G}$ by replacing each of its edge by a path of length 2 . The sum of all the degrees of all the vertices of a graph is equal to twice the total number of its edges is called the Handshaking Lemma.

A number can uniquely identify a graph. A Topological index is a numeric number invariant under the isomorphism of graphs and associated to a graph which completely describes the topology of the graph. The significance of the topological indices is usually associated with quantitative structure-property and relationship (QSPR) and quantitative structure-activity relationship (QSAR).

The study of topological indices was effectively employed in 1947 in chemistry by Wiener [13]. He introduced a distance - based topological indices called Wiener index.The first degree-based connectivity index for graphs developed by the chemist 


\section{Mohanappriya.G and D.Vijayalakshmi}

Randić under the name "branching index" [9] as $R(G)=\left[\Sigma\left(d_{u} d_{v}\right)\right]^{-1 / 2}$, where uv is an edge in $\mathrm{G}$.

Later, this index was generalized for any real number $\alpha$ and known as generalized Randić index:

$$
\mathrm{R}_{\alpha}(\mathrm{G})=\Sigma\left(\mathrm{d}_{\mathrm{u}} \cdot \mathrm{d}_{\mathrm{v}}\right)^{\alpha} \text {. }
$$

$\mathrm{Li}$ and Zhao proposed the first general Zagreb index in [6]:

$$
\mathrm{M}_{\alpha}(\mathrm{G})=\sum_{\mathrm{u} \in \mathrm{V}(\mathrm{G})}\left(\mathrm{d}_{\mathrm{u}}\right)^{\alpha} .
$$

Zhou and Trinajistic introduced the general sum-connectivity index [14]:

$$
\chi_{\alpha}(\mathrm{G})=\underset{\mathrm{u} \in \mathrm{V}(\mathrm{G})}{\sum}\left(\mathrm{d}_{\mathrm{u}}+\mathrm{d}_{\mathrm{v}}\right)^{\alpha} .
$$

Estrada et al introduced the atom-bond connectivity $(A B C)$ index in [2]. The $\mathrm{ABC}$ index of a $\mathrm{G}$ is

$$
\operatorname{ABC}(G)=\Sigma\left[\left(d_{u}+d_{v}-2\right)\right]^{1 / 2}\left[\left(d_{u} \cdot d_{v}\right)\right]^{-1 / 2}
$$

$$
\mathrm{u} \in \mathrm{V}(\mathrm{G})
$$

Vukicevic et al proposed the geometric arithmetic (GA) index in [12]. The GA index of G is defined as

$$
\mathrm{GA}(\mathrm{G})=\underset{\mathrm{u} \in \mathrm{V}(\mathrm{G})}{\Sigma} 2\left[\mathrm{~d}_{\mathrm{u}} \cdot \mathrm{d}_{\mathrm{v}}\right]^{1 / 2}\left[\mathrm{~d}_{\mathrm{u}}+\mathrm{d}_{\mathrm{v}}\right]^{-1}
$$

where, $d_{u}$ is the degree of each vertex in $V(G)$ and uv every edge in $E(G)$.

Recently in [1] Durgi et al found Zagreb indices of semi total point graphs of some graphs. In [3,4,5], Kulli have introduced several degree based new topological indices and studied the same for several nanostructures.

\section{Topological indices of total graphs and line graph of subdivision graphs}

In 2011, Ranjini et al. calculated the explicit expressions for the Shultz indices of the subdivision graphs of the tadpole, wheel, helm and ladder graphs [10]. They also studied the Zagreb indices of the line graphs of subdivision graphs of tadpole, wheel and ladder graphs in [11]. Motivated by the results of $[8,10,11]$, we compute the topological indices of total graph of subdivision graphs of tadpole graph, wheel graph and ladder graph.

Table 1: The edge partition of the graph $T\left(S\left(W_{n+1}\right)\right)$.

\begin{tabular}{lccccccccc}
\hline $\begin{array}{l}\left(\mathrm{d}_{\mathrm{u}}, \mathrm{d}_{\mathrm{v}}\right), \\
\mathrm{uv} \in \mathrm{E}(\mathrm{G})\end{array}$ & $(4,5)$ & $(4,6)$ & $(4, \mathrm{n}+2)$ & $(4,2 \mathrm{n})$ & $(5,5)$ & $(5,6)$ & $(5, \mathrm{n}+2)$ & $(\mathrm{n}+2, \mathrm{n}+2)$ & $(2 \mathrm{n}, \mathrm{n}+2)$ \\
\hline $\begin{array}{l}\text { Number } \\
\text { of Edges }\end{array}$ & $3 \mathrm{n}$ & $3 \mathrm{n}$ & $\mathrm{n}$ & $\mathrm{n}$ & $4 \mathrm{n}$ & $3 \mathrm{n}$ & $\mathrm{n}$ & $(\mathrm{n}(\mathrm{n}-1)) / 2$ & $\mathrm{n}$ \\
\hline
\end{tabular}

Table 2: The edge partition of the graph $\mathrm{T}\left(\mathrm{S}\left(\mathrm{L}_{\mathrm{n}}\right)\right)$.

\begin{tabular}{lllllr}
\hline$\left(\mathrm{d}_{\mathrm{u}}, \mathrm{d}_{\mathrm{v}}\right)$ where uv $\in \mathrm{E}(\mathrm{G})$ & $(4,4)$ & $(4,5)$ & $(4,6)$ & $(5,5)$ & $(5,6)$ \\
\hline Number of Edges & 30 & $(6 n-8)$ & $(6 \mathrm{n}-12)$ & $(6 \mathrm{n}-12)$ & $(9 \mathrm{n}-20)$ \\
\hline
\end{tabular}

Table 3: The edge partition of the graph $\mathrm{T}\left(\mathrm{S}\left(\mathrm{T}_{\mathrm{n}, \mathrm{k}}\right)\right)$.

\begin{tabular}{lcccccccc}
\hline$\left(\mathrm{d}_{\mathrm{u}}, \mathrm{d}_{\mathrm{v}}\right)$ where uv $\in \mathrm{E}(\mathrm{G})$ & $(2,3)$ & $(2,4)$ & $(3,4)$ & $(4,4)$ & $(4,5)$ & $(4,6)$ & $(5,5)$ & $(5,6)$ \\
\hline Number of Edges & 1 & 1 & 2 & $(8 \mathrm{n}+8 \mathrm{k}-18)$ & 6 & 3 & 3 & 3
\end{tabular}


Topological Indices of the Line Graph of the Subdivision Graphs

Proposition 3.1. Let $\mathrm{G}$ be the total graph of subdivision graph of $\mathrm{W}_{\mathrm{n}+1}, \mathrm{n}>4$. Then

$$
\begin{aligned}
& R_{\alpha}(G)=2^{\alpha}\left[n \cdot 5^{\alpha} \cdot 3^{\alpha+1}+n^{\alpha+1}(n+2)^{\alpha}\right]+2^{3 \alpha}\left[n \cdot 3^{\alpha+1}+n^{\alpha+1}\right]+2^{2 \alpha} \cdot n \cdot\left[3 \cdot 5^{\alpha}+(n+2)^{\alpha}\right]+ \\
& +\mathrm{n} \cdot 2^{2} \cdot 5^{2 \alpha}+\mathrm{n} \cdot 5(\mathrm{n}+2)^{\alpha}+(1 / 2)\left(\mathrm{n}(\mathrm{n}-1)\left(\mathrm{n}^{2}+4 \mathrm{n}+4\right)^{\alpha}\right) \text {. } \\
& \mathrm{M}_{\alpha}(\mathrm{G})=\mathrm{n} \cdot 6^{\alpha}+\mathrm{n} \cdot 3 \cdot 5^{\alpha}+\mathrm{n}^{\alpha} \cdot 2^{\alpha}+\mathrm{n} \cdot 2^{2 \alpha+1}+\mathrm{n}(\mathrm{n}+2)^{\alpha} \text {. } \\
& \chi_{\alpha}(\mathrm{G})=\mathrm{n}\left[3\left(3^{2 \alpha}+2^{\alpha} \cdot 5^{\alpha}+11^{\alpha}\right)+(2 \mathrm{n}+4)^{\alpha}\left[(\mathrm{n}+6)^{\alpha}+(1 / 2)(\mathrm{n}-1)\right]+(\mathrm{n}+6)^{\alpha}+(\mathrm{n}+7)^{\alpha}+(3 \mathrm{n}+2)^{\alpha}\right. \\
& \left.+2^{\alpha+1} \cdot 5^{\alpha}\right] \text {. } \\
& A B C(G)=\sqrt{3} n+(1 / 2)[3 n \cdot \sqrt{ }(7 / 5)+n(\sqrt{ }(n+4) / \sqrt{ }(n+2))+n \sqrt{ }(n-1)+n \sqrt{ }(2 n+2) \\
& ((\mathrm{n}-1) /(\mathrm{n}+2))]+((8 \mathrm{n}) / 5) \sqrt{ } 2+((3 \mathrm{n}) / 10) \sqrt{3}+\mathrm{n}[(\sqrt{ }(\mathrm{n}+5) /(\sqrt{ }(5 \mathrm{n}+10)+ \\
& \left.+(\sqrt{ } 3 \mathrm{n}) /\left(\sqrt{ } 2 \mathrm{n}^{2}+4 \mathrm{n}\right)\right] \text {. } \\
& \mathrm{GA}(\mathrm{G})=\mathrm{n}[(4 \sqrt{5}) / 3+(6 \sqrt{3} 0) / 11+(6 \sqrt{ } 6) / 5+(1 /(\mathrm{n}+6)[4 \sqrt{ }(\mathrm{n}+2)+2 \sqrt{ }(5 \mathrm{n}+10)] \\
& \left.+\left(1 /(2 n+4)\left(n^{2}-n-2\right)\right]+(1 /(n+2))(2 n \sqrt{2} n+\sqrt{3} n+2)\right] .
\end{aligned}
$$

Proof: In G, there are $7 \mathrm{n}+1$ nodes, among which $3 \mathrm{n}$ nodes of valency five, $2 \mathrm{n}$ nodes of valency four, $n$ nodes of valency six, $n$ nodes of valency $n+2$ and one node of valency $2 n$. Thus by Handshaking lemma the total number of edges in $G$ is $\left(n^{2}+33 n\right) / 2$. Hence we get the edge partition, based on the valency of the nodes as shown in Table 1, by applying formulas (1)-(5) to the data in Table 1 and by calculation, we obtained the required results.

Corollary 3.1. Let $\mathrm{G}$ be the total graph of the subdivision graph of $\mathrm{W}_{3+1}$. Then

$\mathrm{R}_{\alpha}(\mathrm{G})=2^{3 \alpha+2} 3^{\alpha+1}+2 \cdot 3^{2} \cdot 5^{2 \alpha}+5^{\alpha}\left[2^{2} \cdot 3^{\alpha+1}+3 \cdot 2^{2 \alpha+2}\right]$

$\mathrm{M}_{\alpha}(\mathrm{G})=3^{\alpha} \cdot 2^{2 \alpha+1}+2 \cdot 3\left[5^{\alpha}+2^{2 \alpha}\right]$

$\chi_{\alpha}(\mathrm{G})=3.5^{\alpha}\left[2^{\alpha+2}+3.2^{\alpha+1}\right]+2^{2} \cdot 3\left[11^{\alpha+} 3^{2 \alpha}\right]$

$\mathrm{ABC}(\mathrm{G})=2^{2} \sqrt{3}+(6 / 5)[\sqrt{ } 30+\sqrt{ } 35+6 \sqrt{2}]$

$\mathrm{GA}(\mathrm{G})=18+(24 / 5) \sqrt{ } 6+(24 / 11) \sqrt{ } 30+(16 / 3) \sqrt{ } 5$.

Corollary 3.2. Let $\mathrm{G}$ be the total graph of the subdivision graph of $\mathrm{W}_{4+1}$. Then

$\mathrm{R}_{\alpha}(\mathrm{G})=6^{2 \alpha+1}+2^{2}\left(2^{2} \cdot 5^{2 \alpha}+2^{5 \alpha}\right)+3^{\alpha}\left[2^{4 \alpha+2}+2^{3 \alpha+4}+5^{\alpha}\left(2^{\alpha+4}+6^{2 \alpha+2}\right)\right]$

$\mathrm{M}_{\alpha}(\mathrm{G})=2^{3 \alpha}+2^{2}\left[3 \cdot 2^{\alpha+1}+3 \cdot 5^{\alpha}+2^{2 \alpha+1}\right]$

$\chi_{\alpha}(\mathrm{G})=5^{\alpha} \cdot 2^{\alpha+5}+7^{\alpha} \cdot 2^{\alpha+2}+11^{\alpha} \cdot 2^{4}+3^{\alpha}\left[3 \cdot 2^{2 \alpha+1}+2^{2 \alpha+2}+2^{2} \cdot 3^{\alpha+1}\right]$

$\mathrm{ABC}(\mathrm{G})=2+\sqrt{ } 5+(8 / 3)[\sqrt{ } 10+2 \sqrt{ } 3]+(2 / 5)[4 \sqrt{ } 30+3 \sqrt{ } 35+16 \sqrt{2}]$

$\mathrm{GA}(\mathrm{G})=22+(2 / 3)[\sqrt{ } 32+4 \sqrt{ } 20]+(16 / 5) \sqrt{ } 24+(4 / 7) \sqrt{ } 48+(32 / 11) \sqrt{ } 30$.

Proposition 3.2. Let $\mathrm{G}$ be the total graph of subdivision graph of $\mathrm{L}_{\mathrm{n}}$. Then

$\mathrm{R}_{\alpha}(\mathrm{G})=3.5 \cdot 2^{4 \alpha+1}+5^{2 \alpha}[9 \mathrm{n}-20]+5^{\alpha .} .2^{2 \alpha+1}[3 \mathrm{n}-4]+2^{3 \alpha+2} 3^{\alpha+1}[\mathrm{n}-2]$.

$\mathrm{M}_{\alpha}(\mathrm{G})=2^{2 \alpha}[3 \mathrm{n}+10]+[\mathrm{n}-2]\left[2 \cdot 3 \cdot 5^{\alpha}+3^{\alpha} \cdot 2^{\alpha+1}\right]$.

$\chi_{\alpha}(\mathrm{G})=2(3 \mathrm{n}-4)\left[3^{2 \alpha}+11^{\alpha}\right]+5^{\alpha}\left[2^{\alpha}(9 \mathrm{n}-20)+2^{\alpha+1}(3 \mathrm{n}-6)\right]+3.5 .2^{3 \alpha+1}$.

$\mathrm{ABC}(\mathrm{G})=\sqrt{3}(2 \mathrm{n}-4)+(15 / 2) \sqrt{6}+(1 / 5)[2 \sqrt{2}(9 n-2)+(3 n-4) \sqrt{ } 35+(3 n-6) \sqrt{30}]$.

$\mathrm{GA}(\mathrm{G})=30+(9 \mathrm{n}-20)+(4 / 9) \sqrt{ } 5(6 \mathrm{n}-8)+(4 / 5) \sqrt{ } 6(3 \mathrm{n}-4)+(4 / 11) \sqrt{ } 30(3 n-4)$.

Proof: In G, there are $11 n-6$ nodes, among which $3 n+10$ nodes of valency four, $6 n-12$ nodes of valency five and $2 \mathrm{n}-4$ nodes of valency six. Thus by, Handshaking lemma there are $27 n-22$ edges in G. Hence we get the edge partition, based on the valency of the nodes as shown in Table 2, by applying formulas (1) - (5) to the data in Table 2 and by calculation, we obtained the required results. 
Corollary 3.3. Let $\mathrm{G}$ be the total graph of subdivision graph of $\mathrm{L}_{2}$. Then

$\mathrm{R}_{\alpha}(\mathrm{G})=2^{4 \alpha+4}$

$\mathrm{M}_{\alpha}(\mathrm{G})=2^{2 \alpha+4}$

$\chi_{\alpha}(\mathrm{G})=2^{3 \alpha+4}$

$\mathrm{ABC}(\mathrm{G})=4 \sqrt{6}$

$\mathrm{GA}(\mathrm{G})=64$.

Proposition 3.3. Let $\mathrm{G}$ be the total graph of subdivision graph of $\mathrm{T}_{\mathrm{n}, \mathrm{k}}$. Then

$\mathrm{R}_{\alpha}(\mathrm{G})=2^{\alpha}\left[3^{\alpha}+3^{\alpha+1} \cdot 5^{\alpha}\right]+2^{3 \alpha}\left[3^{\alpha+1}+1\right]+2^{2 \alpha+1}\left[3^{\alpha}+3 \cdot 5^{\alpha}\right]+2^{4 \alpha+1}[4 \mathrm{n}+4 \mathrm{k}-9]+3 \cdot 5^{2 \alpha}$

$\mathrm{M}_{\alpha}(\mathrm{G})=2^{\alpha}+3.5^{\alpha}+3^{\alpha}\left[1+2^{\alpha}\right]+2^{2 \alpha+1}[2 \mathrm{n}+2 \mathrm{k}-3]$

$\chi_{\alpha}(\mathrm{G})=3 \cdot 11^{\alpha}+5^{\alpha}+2\left[3^{\alpha}+7^{\alpha}+3^{2 \alpha+1}\right]+3 \cdot 5^{\alpha} \cdot 2^{\alpha+1}+2^{3 \alpha+1}[4 \mathrm{n}+4 \mathrm{k}-9]$

$\mathrm{ABC}(\mathrm{G})=\sqrt{ } 2+\sqrt{3}+(\sqrt{5} \sqrt{3}) / 3+(\sqrt{6} / 2)[4 \mathrm{n}+4 \mathrm{k}-9]+(1 / 5)[3 \sqrt{ } 35+6 \sqrt{2}+(3 / 2) \sqrt{ } 30]$

$\mathrm{GA}(\mathrm{G})=3+2[4 \mathrm{n}+4 \mathrm{k}-9]+(2 / 3)(\sqrt{2}+4 \sqrt{5})+(2 / 5)(\sqrt{ } 6+6)+(1 / 7)\left(2^{3} \sqrt{ } 3\right)+(6 / 11)(\sqrt{ } 30)$

Proof: In G, there are $(4 n+4 k)$ nodes, among which $4 n+4 k-9$ nodes of valency four, three nodes of valency five, one vertex of valency two, one node of valency three and a node of valency six. Thus by Handshaking lemma there are $(8 n+8 k+1)$ edges in G. Hence we get the edge partition, based on the valency of the nodes as shown in Table 3, by applying formulas (1) - (5) to the data in Table 3 and by calculation, we obtained the required results.

\section{Conclusion}

In this paper, we compute some degree based topological indices such as generalized Randić index, first general Zagreb index, geometric arithmetic index, atom-bond connectivity index and general sum-connectivity index of the total graph of the tadpole graphs, wheel graphs and ladder graphs using the subdivision concept.

\section{REFERENCES}

1. B.S.Durgi, S.M.Mekkalike, H.S.Ramane and S.P.Hande, On the Zagreb indices of Semi total point graphs of some graphs, Annals of Pure and Applied Mathematics, 12(1) (2016) 49-57.

2. E.Estrada, L.Torres, L.Rodriguez and I.Gutman, An atom-bond connectivity index: modeling the enthalpy of formation of alkanes, Indian Journal of Chemistry, 37A (1998) 849-855.

3. V.R.Kulli, Two new multiplicative atom bond connectivity indices, Annals of Pure and Applied Mathematics, 13(1) (2017) 1-7.

4. V.R.Kulli, New arithmetic geometric indices, Annals of Pure and Applied Mathematics, 13(2) (2017) 165-172.

5. V.R.Kulli, The Gourava indices and co-indices, Annals of Pure and Applied Mathematics, 14(1) (2017) 33-38.

6. X.Li and H.Zhao, Trees with the first three smallest and largest generalized topological indices, MATCH Communications in Mathematical and in Computer Chemistry, 50 (2004) 57-62.

7. M.Capobianco and J.C.Molluzzo, Examples and Counter examples in Graph Theory, Elsevier Science Ltd (1978). 
Topological Indices of the Line Graph of the Subdivision Graphs

8. M.F.Nadeem, S.Zafar and Z.Zahid, On certain topological indices of the line graph of subdivision graphs, Applied Mathematics and Computation, 271 (C) (2015) 790-794.

9. M.Randic, On characterization of molecular branching, Journal of American Chemical Society, 97 (1975) 6609-6615.

10. P.S.Ranjini, V.Lokesha and M.A.Rajan, On the Shultz index of the subdivision graphs, Advanced Studies in Contemporary Mathematics, 21 (3) (2011) 279-290.

11. P.S.Ranjini, V.Lokesha and I.N.Cangl, On the Zagreb indices of the line graphs of the subdivision graphs, Applied Mathematics and Computation, 218 (2011) 699-702.

12. D.Vukicevic and B.Furtula, Topological index based on the ratios of geometrical and arithmetical means of end-vertex valency of edges, Journal of Mathematical Chemistry, 46 (2009) 1369-1376.

13. H.J.Wiener, Structural determination of paraffin boiling points, Journal of American Chemical Society, 69 (1947) 17-20.

14. B.Zhou and N.Trinajstic, On general sum-connectivity index, Journal of Mathematical Chemistry, 47 (2010) 210-218. 